\title{
EFFECT OF FILLER ON WELD METAL STRUCTURE OF AA6061 ALUMINUM ALLOY BY TUNGSTEN INERT GAS WELDING
}

\author{
M. Ishak ${ }^{1,2}$, N.F.M. Noordin ${ }^{1}$, A.S.K. Razali ${ }^{1}$, L.H.A. Shah ${ }^{1,2}$ and F.R.M. Romlay ${ }^{1,2}$ \\ ${ }^{1}$ Manufacturing Focus Group, \\ Faculty of Mechanical Engineering, Universiti Malaysia Pahang, \\ 26600 Pekan, Pahang, Malaysia \\ Email: mahadzir@ump.edu.my \\ Phone: +6094246239; Fax: +6094246222 \\ ${ }^{2}$ Automotive Engineering Centre, Universiti Malaysia Pahang, \\ 26600 Pekan, Pahang, Malaysia
}

\begin{abstract}
Innovative welding technology in joining aluminum alloys in the automobile, aviation, aerospace and marine industries would achieve weight reduction and high specific strength as well as increasing fuel efficiency and reducing environmental pollution. This study presents an appropriate welding filler to join similar AA6061 aluminum alloys using the tungsten inert gas (TIG) process. The TIG welding of AA6061 was butt joined with three different fillers: ER5356 (4.5-6\% Mg), ER4043 (4.5-6\% Si) and ER4047 $(11-13 \% \mathrm{Si})$. The experiments were conducted in order to investigate the macrostructure and microstructure of the samples as well as the mechanical properties. The effect of preheating was also investigated. The effects of the different fillers used on the weld joints were analyzed by their visual appearance, microstructures, hardness and strength. It was found that welding by using filler ER5356 produced a finer grain size and the highest strength of $171.53 \mathrm{MPa}$ compared to the weld joints using fillers ER4047 and ER4047 with values of 167.34 MPa and 168.03 MPa, respectively.
\end{abstract}

Keywords: AA6061; TIG; ER5356; ER4043; ER4047.

\section{INTRODUCTION}

Aluminum alloy is a silverish white metal that has strong resistance to corrosion. Compared to other materials like steel, brass or nickel, this material is lighter. Aluminum alloys are currently used in various sectors because of their higher quality characteristics like low specific gravity, corrosion resistance and recyclability [1-3]. Nowadays, their application is still expanding, mostly in the automobile and aerospace industries [4-6]. As shown in the study by Fortain and Gadrey [7], the main applications of aluminum products have been in transportation (27\%), construction (20\%), packaging (16\%), electricity supply (10\%), machinery and equipment $(8 \%)$ and also in sectors relating to sustainable products $(7 \%)$ where extraordinary growth reaching 60 million tons by 2020 has been predicted. The aluminum alloys from the 6000 family series has been the most considered for substantial use in industry. This arises from its appropriate weldability and high corrosion behavior (Fahimpour et al. [8]; Mutombo and Toit [9]). In particular in this family, such as in 6061, the most commonly used material which is the main alloying element is silicon ( $\mathrm{Si}$ ). Due to this behavior, 
AA6061 has found wide usage in welded structural members, such as truck and marine frames, railroad cars and pipelines (Luijendijk [10]; Ramanaiah et al. [11]).

In order to fulfill this industrial demand, the fabrication of structural bodies involves, in most instances, the application of a joining process, which is, combining one part with another. The preferred welding process for these alloys is frequently gas tungsten arc welding (GTAW) or also known as tungsten inert gas (TIG) welding. Undeniably, this type of welding is most popular due to its simplicity, versatility, rapidity and ease of training (Sevim et al. [12]; Zakaria et al. [13]). However, welding of this alloy still remains a challenge. Usually, welded Al-Mg-Si alloys have problems, such as low fracture toughness in the heat-affected zone (HAZ) near a weldment due to liquation cracking (Kumar and Sundarrajan [14]). The existence of liquation cracks has a negative effect on the mechanical properties. Other difficulties in the joint, such as the presence of the oxide layer, high solubility of hydrogen and other gases in the molten state, and solidification shrinkage can occur during the welding process. The deterioration in the mechanical properties is due to the heat applied during the welding process. According to previous studies, the problems that occur during the joining of alloy 6061 by metal inert gas (MIG) welding, can be avoided by choosing the right filler. As stated by Mosneaga et al. [1], using filler with the addition of a small amount of $\mathrm{Mn}$ is effective in suppressing recrystallization, which leads to a drastic decrease in fracture toughness through liquation cracking. Therefore, the selection of the filler metal is one of the most important aspects that need to be considered in TIG welding. In this study, the effect of Si-rich and Mg-rich filler, ER5356 (Mg-rich), ER4043 (Si-rich) and ER4047 (Si-rich), on the mechanical properties of welding joints is investigated. Moreover, the microstructure changes were also identified.

\section{EXPERIMENTAL SET UP}

\section{Materials}

In this investigation, the materials used were $\mathrm{Al}-\mathrm{Si}-\mathrm{Mg}$ aluminum alloys, namely AA6061. The material thickness is $2 \mathrm{~mm}$ and the compositions of the materials and filler metals used are as shown in Table 1.

Table 1. Compositions of materials and filler metals.

\begin{tabular}{llllllll}
\hline & $\mathrm{Al}$ & $\mathrm{Si}$ & $\mathrm{Fe}$ & $\mathrm{Cu}$ & $\mathrm{Mn}$ & $\mathrm{Mg}$ & $\mathrm{Zn}$ \\
\hline AA6061 & 97.3 & 0.890 & 0.33 & 0.29 & 0.025 & 0.86 & 0.007 \\
ER5356 & Bal & 0.25 & 0.4 & - & - & 5.5 & 0.10 \\
ER4043 & Bal & 6.0 & 0.8 & - & - & 0.05 & 0.10 \\
ER4047 & Bal & 13.0 & 0.8 & - & - & 0.10 & 0.10 \\
\hline
\end{tabular}

\section{Experimental Procedure}

The 6061 aluminum alloy was cut into a square $150 \mathrm{~mm} \times 150 \mathrm{~mm}$ using an MVS-C $6 / 31$ shearing machine. After the cutting process, aluminum 6061 was butt joined to a similar base material using the TIG Syncrowave200 Model Miller welding machine and the process was carried out by AC-TIG welding sources subjected to welding currents of $60 \mathrm{~A}$ and $70 \mathrm{~A}$ and preheating temperatures of $80^{\circ} \mathrm{C}$ and $120^{\circ} \mathrm{C}$, as shown in Table 2. The tensile strength of the welded specimen can be improved by increasing the 
preheating temperature. After that, the specimens were cut into $20 \mathrm{~mm}$ strips as shown in Figure 1. The specimens were then hot mounted, ground and polished. The specimens were etched by Keller Reagent for microstructural observation. The hardness of the weld was measured with a Matsuzawa MMT-

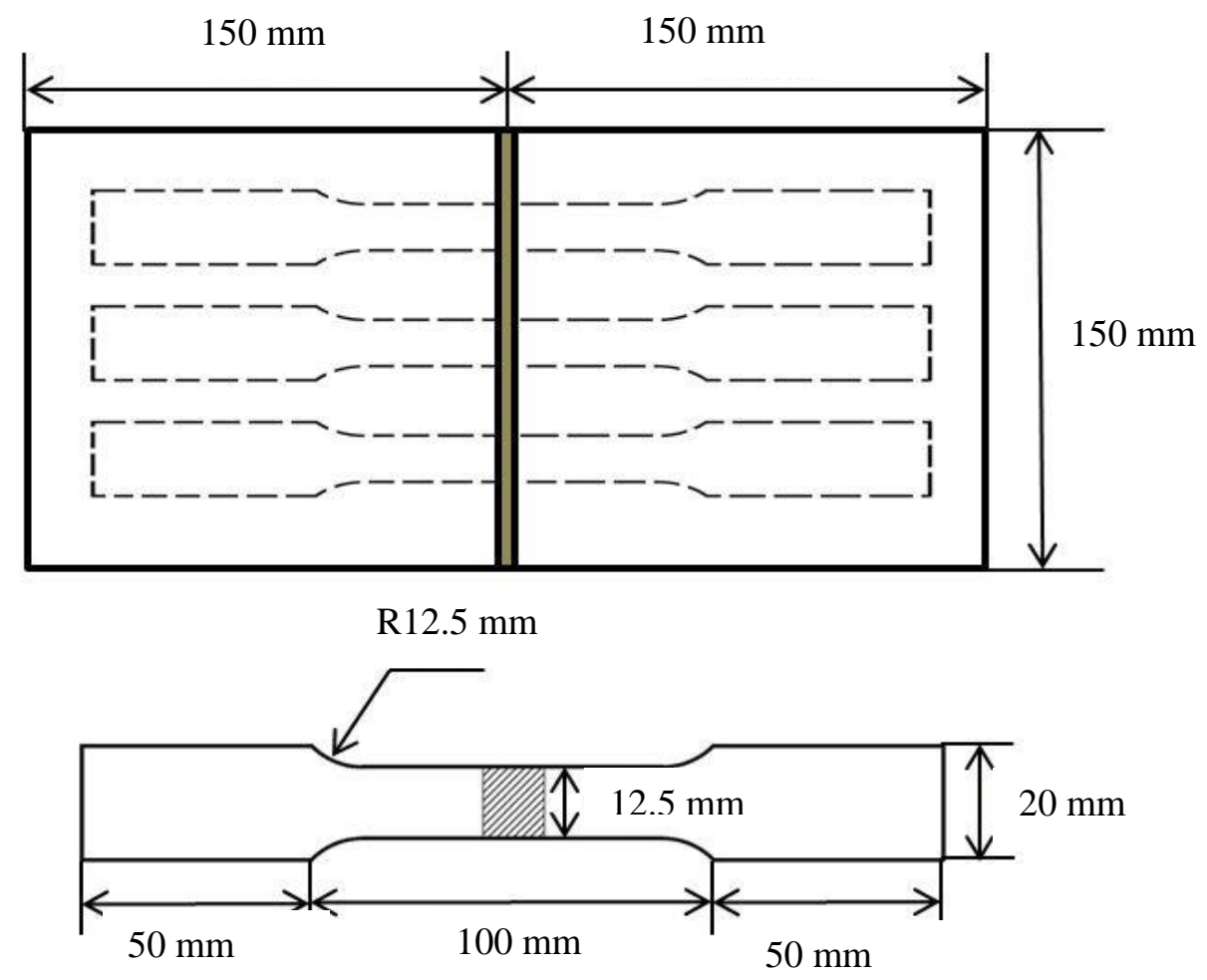

Figure 1. Schematic illustration of the butt joint welding setup and design for the tensile test.

\section{RESULTS AND DISCUSSION}

\section{Macrostructures}

The macrostructures of the weld cross sectional area of the AA6061 was obtained by using an optical microscope. Twelve (12) specimens were observed. The specimens welded using ER5356, ER4043 and ER4047 are shown in Figure 2. In these specimens, defects such as lack of fusion and distortion are observed. However, among these twelve specimens, three specimens were selected for microstructural analysis, namely specimens 3, 8 and 10 as shown in Figure 2. These specimens were selected based on their weld appearance, such as fewer defects and their high tensile values. The results of the tensile test for all specimens are shown in Table 2. The highest tensile value for filler ER5356 is specimen 3 at $70 \mathrm{~A}$ and $80^{\circ} \mathrm{C}$ preheating temperature with heat input given as $812.90 \mathrm{~J}$. For filler ER4043, specimen 8 produced the highest tensile strength value using parameters of $70 \mathrm{~A}$ and $120^{\circ} \mathrm{C}$ preheating temperature with heat input applied at $482.05 \mathrm{~J}$. For filler ER4047, specimen 10 produced the highest tensile strength value at $60 \mathrm{~A}$ and $120^{\circ} \mathrm{C}$ preheat temperature with heat input applied at $593.18 \mathrm{~J}$. 


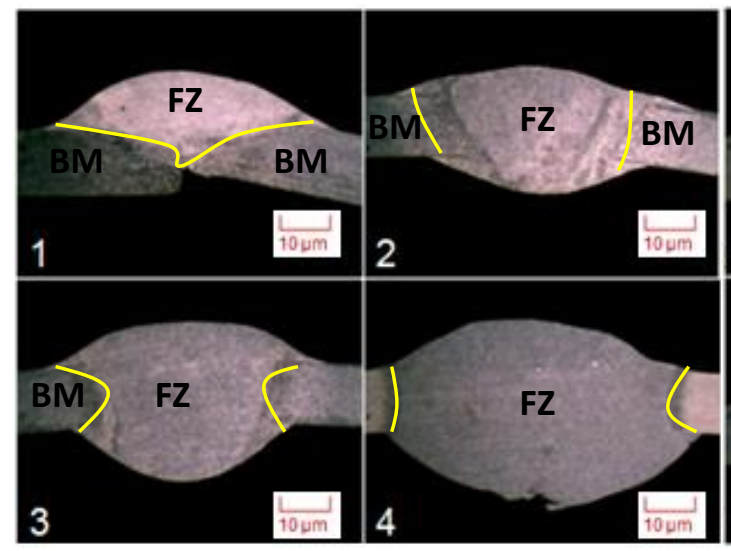

(a)

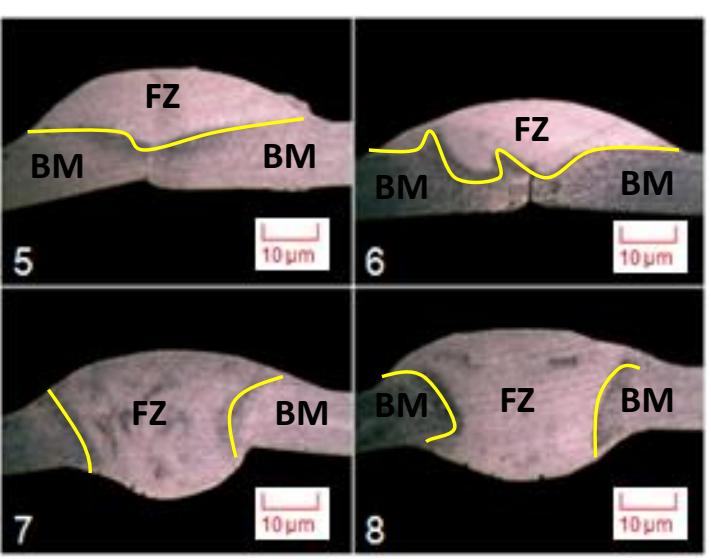

(b)

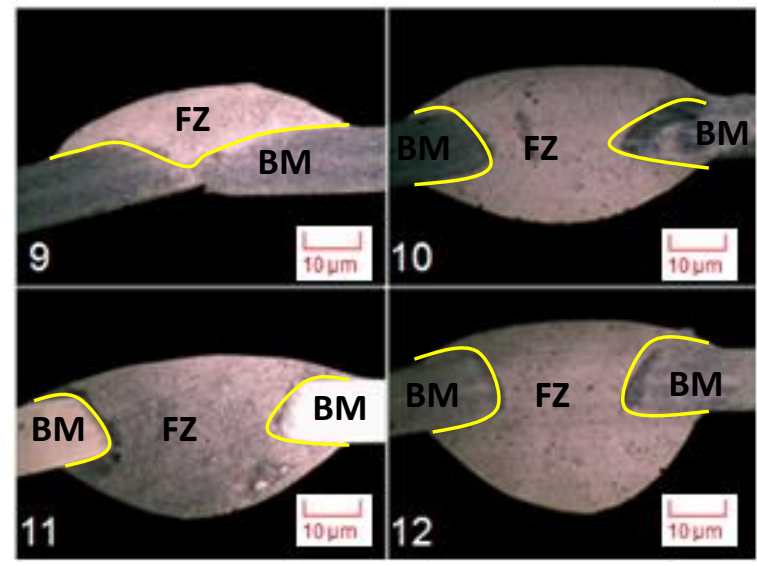

(c)

Figure 2. Cross sections of the welding samples with respective numbering using (a) filler ER5356, (b) filler ER4043 and (c) filler ER4047.

Table 2. Welding parameters.

\begin{tabular}{|c|c|c|c|c|c|c|}
\hline No & $\begin{array}{l}\text { Current } \\
\text { (A) }\end{array}$ & $\begin{array}{l}\text { Preheat } \\
\left({ }^{\circ} \mathrm{C}\right)\end{array}$ & $\begin{array}{c}\text { Voltage } \\
\text { (V) }\end{array}$ & Time Taken $(\mathrm{L}=150 \mathrm{~mm})$ & $\begin{array}{l}\text { Heat Input } \\
(\mathrm{J})\end{array}$ & $\begin{array}{c}\text { Tensile Test } \\
(\mathrm{MPa})\end{array}$ \\
\hline \multicolumn{7}{|c|}{ ER5356 } \\
\hline 1 & 60 & 80 & 17.1 & $2 \mathrm{~min} 46 \mathrm{sec}$ & 1140.0 & 83.75 \\
\hline 2 & 60 & 120 & 17.4 & $1 \mathrm{~min} 53 \mathrm{sec}$ & 784.96 & 165.51 \\
\hline 3 & 70 & 80 & 18.0 & $1 \mathrm{~min} 37 \mathrm{sec}$ & 812.90 & 171.53 \\
\hline 4 & 70 & 120 & 18.4 & $1 \mathrm{~min} 10 \mathrm{sec}$ & 601.87 & 162.04 \\
\hline \multicolumn{7}{|c|}{ ER4043 } \\
\hline 5 & 60 & 80 & 17.4 & $1 \mathrm{~min} 53 \mathrm{sec}$ & 784.96 & 47.68 \\
\hline 6 & 60 & 120 & 17.4 & $1 \mathrm{~min} 3 \mathrm{sec}$ & 438.66 & 48.92 \\
\hline 7 & 70 & 80 & 18.3 & $1 \mathrm{~min} 17 \mathrm{sec}$ & 656.92 & 166.80 \\
\hline 8 & 70 & 120 & 18.8 & $55 \mathrm{sec}$ & 482.05 & 167.34 \\
\hline \multicolumn{7}{|c|}{ ER4047 } \\
\hline 9 & 60 & 80 & 17.4 & $2 \min 2 \mathrm{sec}$ & 848.78 & 25.86 \\
\hline 10 & 60 & 120 & 17.4 & $1 \mathrm{~min} 25 \mathrm{sec}$ & 593.18 & 168.03 \\
\hline 11 & 70 & 80 & 18.3 & $1 \mathrm{~min} 3 \mathrm{sec}$ & 538.24 & 166.49 \\
\hline 12 & 70 & 120 & 18.8 & $53 \mathrm{sec}$ & 465.02 & 166.19 \\
\hline
\end{tabular}




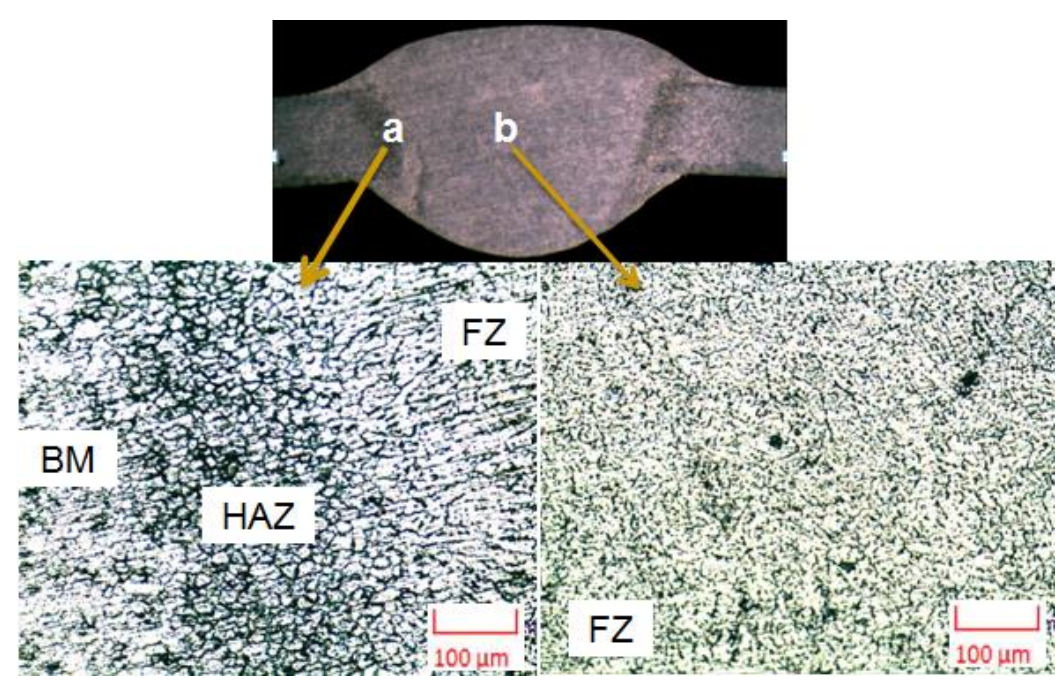

(a)

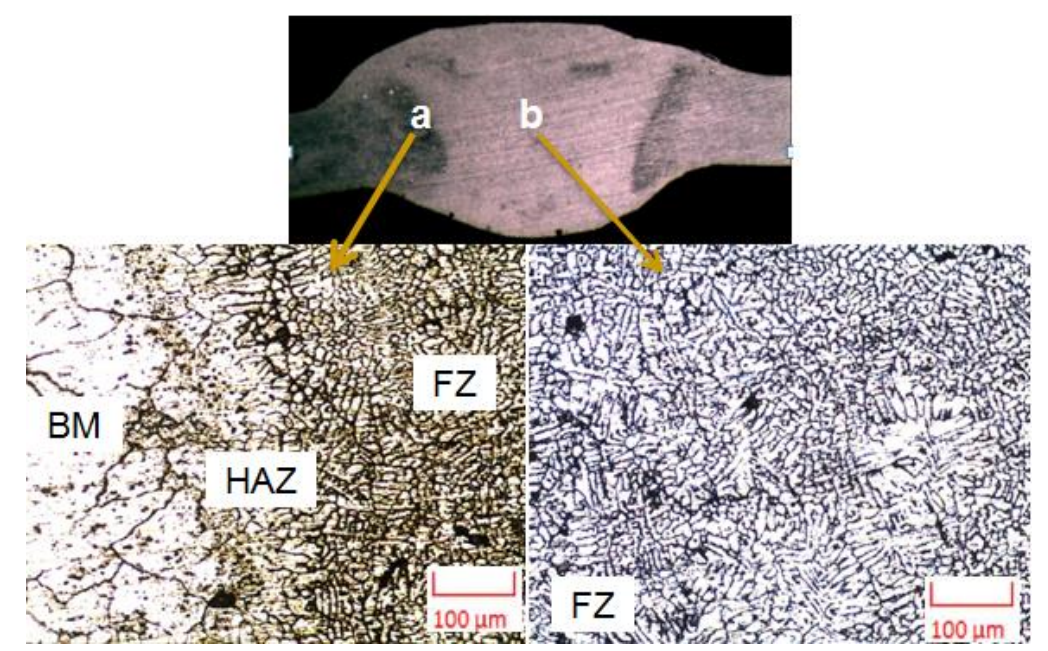

(b)

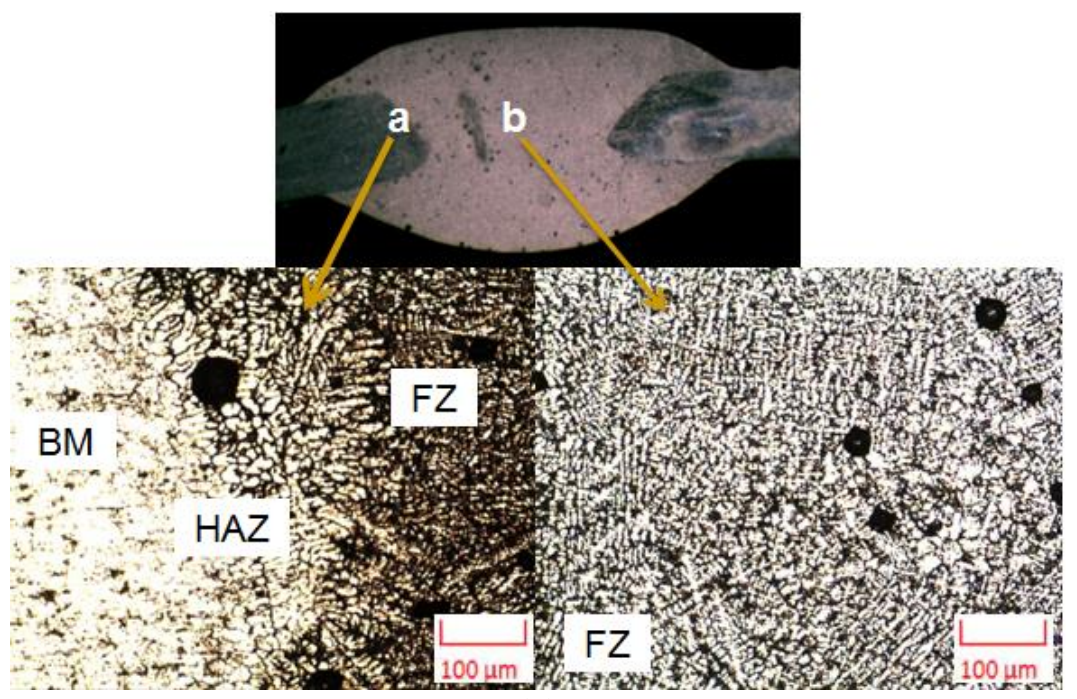

(c)

Figure 3. Weld microstructure using (a) filler ER5356, (b) filler ER4043 and (c) filler ER4047. 


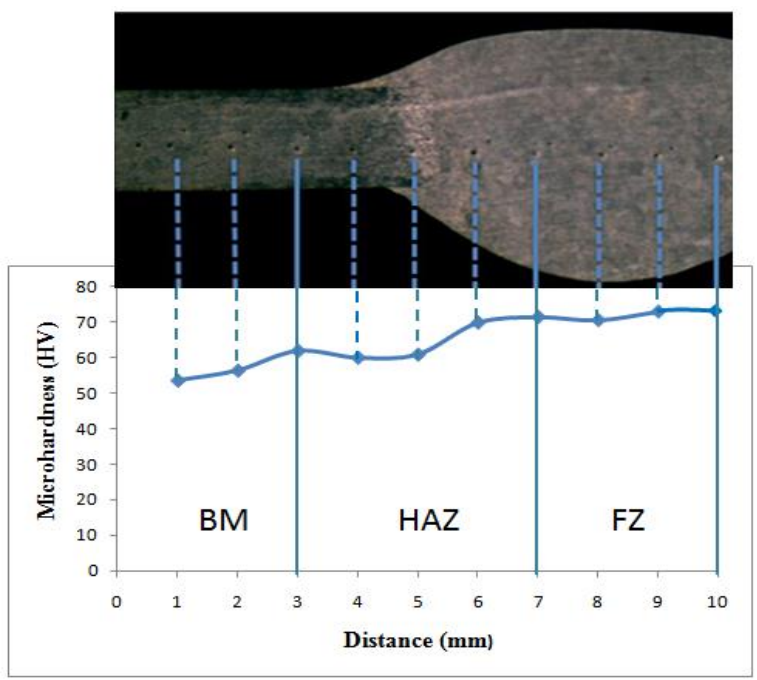

(a)

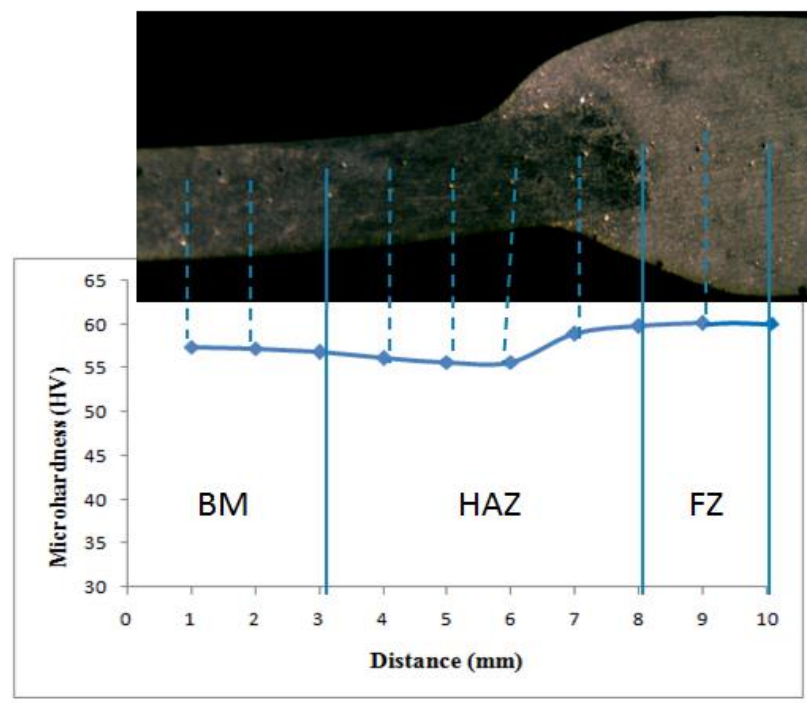

(b)

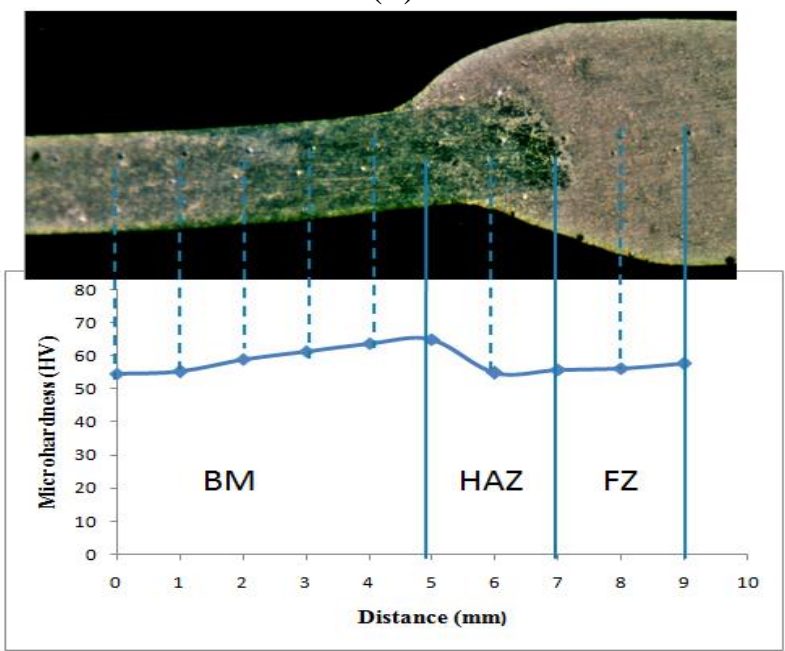

(c)

Figure 4. Hardness value of weld joint by using (a) filler ER5356, (b) filler ER4043 and (c) filler ER4047. 


\section{Microstructures}

The cross sections and microstructures of specimens 3, 8 and 10 are shown in Figure 3. The microstructures have been labeled with several types of formation boundaries such as fusion zone (FZ), HAZ, partially melted zone (PMZ) and base metal (BM). The grain size observed at the FZ for welds with ER5356 is $25.69 \mu \mathrm{m}$, as shown in Figure 3 (a), while the welds with fillers ER4043 and ER4047 have larger grain sizes of $52.75 \mu \mathrm{m}$ and $76.78 \mu \mathrm{m}$, respectively, as shown in Figures 3 (b) and (c). The smaller the grain size, the higher the strength and hardness produced (Shah et al. [2]).

\section{Hardness Test}

The hardness value across the weld cross section is illustrated using a Vickers hardness testing machine and the results are plotted as shown in Figure 4. These figures show the hardness profiles of all three selected samples in different sections, BM, HAZ and FZ. In the FZ, the highest average hardness value was obtained at $67.07 \mathrm{HV}$ using the ER5356 filler at a current of $70 \mathrm{~A}$ and $120^{\circ} \mathrm{C}$ preheating temperature. The average hardness value at the FZ for the other two samples using fillers ER4043 and ER4047 were $60.05 \mathrm{HV}$ and $56.9 \mathrm{HV}$, respectively. On the other hand, the HAZ section shows a reduction in value compared with the FZ for all samples using fillers ER5356, ER4043 and ER4047 with the average hardness value obtained as $61.9 \mathrm{HV}, 59.08 \mathrm{HV}$ and $55.25 \mathrm{HV}$, respectively.

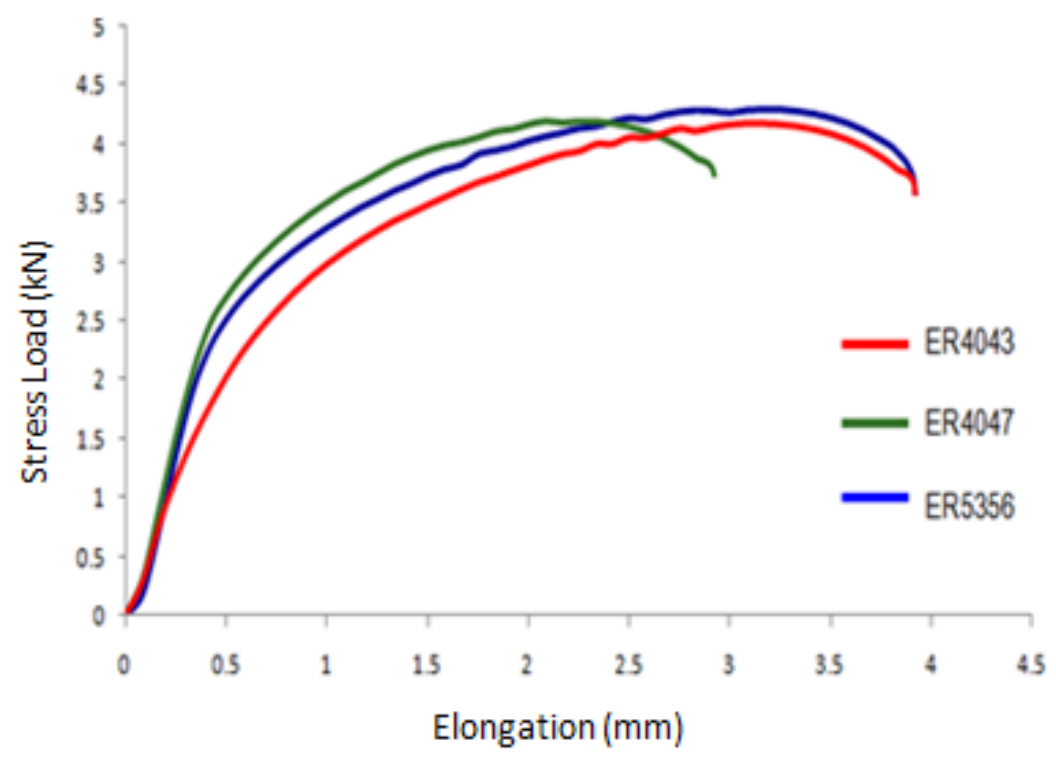

Figure 5. The tensile test using three different filler metals

\section{Tensile Test}

Figure 5 illustrates the tensile test using the three different filler metals. The load given to undertake this process is $50 \mathrm{kN}$ and the crosshead speed to pull the specimens is $1 \mathrm{~min} / \mathrm{mm}$. The tensile strength values increase for all three specimens up to a certain point. The joining strength using ER5356 yields the highest value of $171.53 \mathrm{MPa}$ compared to joining using fillers ER4043 and ER5356 which yield 167.34 MPa and 
168.03 MPa, respectively. The effect of preheating on average tensile stress was observed by using currents of $60 \mathrm{~A}$ and $70 \mathrm{~A}$. All specimens were preheated at temperatures of $80^{\circ} \mathrm{C}$ to $120^{\circ} \mathrm{C}$. Preheating is the process of heating or increasing the temperature at the facing surface before welding. The tensile stress results improved as the preheating temperatures increased. However, the joining strength is higher at a current of $60 \mathrm{~A}$ compared to $70 \mathrm{~A}$.

\section{CONCLUSIONS}

In this paper, the effects of different filler wires used in the TIG welding process were investigated. Based on the present investigation, the following conclusions can be drawn. First, it was found that welding using filler ER5356 produced a finer grain size at the FZ of $25.69 \mu \mathrm{m}$ compared to fillers ER4043 and ER4047 with grain sizes of $52.75 \mu \mathrm{m}$ and $76.78 \mu \mathrm{m}$, respectively. Using filler ER5356 also produced the highest hardness value of $72.9 \mathrm{HV}$ compared to the ER4043 and ER4047 counterparts, with $59.3 \mathrm{HV}$ and $57.6 \mathrm{HV}$, respectively. As for the tensile test result, the weld joints using filler ER5356 had the highest strength of $171.53 \mathrm{MPa}$ compared to the weld joints using fillers ER4043 and ER4047 with values of $167.34 \mathrm{MPa}$ and $168.03 \mathrm{MPa}$, respectively. It can be concluded that TIG welding using ER5356 filler yields better joints compared to ER4043 and ER4047. In addition, for further study, deep investigation into the effects of preheating is proposed in order to ascertain the best quality joint.

\section{ACKNOWLEDGEMENTS}

The author would like to thank the supervisor and technical staffs in Universiti Malaysia Pahang, all of the work within which experiment were conducted. The financial support by Ministry of Education Malaysia through Universiti Malaysia Pahang for Fundamental Research Grant Scheme (FRGS) project no FRGS/1/2013/TKOI/02/2 is also grateful acknowledge.

\section{REFERENCES}

[1] Mosneaga VA, Mizutani T, Kobayashi T, Toda H. Impact Toughness of Weldments in Al-Mg-Si Alloys. Materials Transactions. 2002;43:1381 - 9.

[2] Shah LH, Akhtar Z, Ishak M. Investigation of aluminum-stainless steel dissimilar weld quality using different filler metals. International Journal of Automotive and Mechanical Engineering. 2013;8:1121-31.

[3] Ishak M, Shah LH, Aisha ISR, Hafizi W, Islam MR. Study of resistance spot welding between aisi 301 stainless steel and AISI 1020 carbon steel dissimilar alloys. Journal of Mechanical Engineering and Sciences. 2014;6:793-806.

[4] Karunakaran N. Effect of Pulsed Current on Temperature distribution and characteristics of GTA welded magnesium alloy. IOSR Journal of Mechanical and Civil Engineering. 2013;4(6):1-8.

[5] Najiha MS, Rahman MM, Kamal M, Yusoff AR, Kadirgama K. Minimum quantity lubricant flow analysis in end milling processes: A computational fluid dynamics approach. Journal of Mechanical Engineering and Sciences. 2012;3:340-5.

[6] Puvanesan M, Rahman MM, Najiha MS, Kadirgama K. Experimental investigation of minimum quantity lubrication on tool wear in aluminum alloy 
6061-t6 using different cutting tools. International Journal of Automotive and Mechanical Engineering. 2014;9:1538-49.

[7] Fortain JM, Gadrey S. How to select a suitable shielding gas to improve the performance of MIG and TIG welding of aluminium alloys. Welding International. 2013;27:936-47.

[8] Fahimpour V, Sadrnezhaad SK, Karimzadeh F. Corrosion behavior of aluminum 6061 alloy joined by friction stir welding and gas tungsten arc welding methods. Materials \& Design. 2012;39:329-33.

[9] Mutombo K, Toit Md. Corrosion fatigue behaviour of aluminium alloy 6061T651 welded using fully automatic gas metal arc welding and ER5183 filler alloy. International Journal of Fatigue. 2011;33:1539-47.

[10] Luijendijk T. Welding of dissimilar aluminium alloys. Journal of Materials Processing Technology. 2000; 103(1):29-35.

[11] Ramanaiah N, Balakrishna B, Rao KP. Effect of Modified AA5356 Filler on Corrosion Behavior of AA6061 Alloy GTA Welds. International Journal of Modern Engineering Research. 2012;2:4429-33.

[12] Sevim I, Hayat F, Kaya Y, Kahraman N, Şahin S. The study of MIG weldability of heat-treated aluminum alloys. The International Journal of Advanced Manufacturing Technology. 2012;66:1825-34.

[13] Zakaria KA, Abdullah S, Ghazali MJ. Comparative study of fatigue life behaviour of AA6061 and AA7075 alloys under spectrum loadings. Materials \& Design. 2013;49:48-57.

[14] Kumar A, Sundarrajan S. Selection of welding process parameters for the optimum butt-joint strength of an aluminum alloy. Materials and Manufacturing Processes. 2006;21:779-82. 